\title{
The Heterogeneity and Controversy of C1q Nephropathy: A Report of Two Cases and Review of the Literature
}

\author{
Sufia Husaina, b, Hala Kfoury ${ }^{\mathrm{a}}$
}

\begin{abstract}
$\mathrm{C} 1 \mathrm{q}$ is an uncommon, controversial and under-recognized entity. There is disagreement regarding whether it is an established disease or just part of the spectrum of minimal change disease and focal segmental glomerulosclerosis. C1q nephropathy is diagnosed solely by kidney biopsy. We report two cases of C1q nephropathy, one in a 39-year-old man and the other in an 8-year-old boy. Our two cases highlight the variable nature of this disease. In this article, we present our cases, review the criteria for diagnosis and highlight the heterogeneous nature of this disease in terms of clinical presentation, renal biopsy and variable outcomes. We also discuss the postulated etiopathogenetic mechanisms and note the reported associations.
\end{abstract}

Keywords: C1q nephropathy; Kidney biopsy; Minimal change disease; Focal segmental glomerular sclerosis

\section{Introduction}

The C1q nephropathy $(\mathrm{C} 1 \mathrm{qN})$ pattern was first described in 1982 [1]. By 1985, Jennette and Hipp defined the criteria for the diagnosis of this condition $[2,3]$. The diagnosis is determined solely by kidney biopsy. The diagnostic criteria include the following: 1) diffuse, dominant/co-dominant $\mathrm{C} 1 \mathrm{q}$ deposition in the glomerular mesangium on immunofluorescence (IF), with a minimum staining intensity of 2 on a scale of 0 to 4,2 ) corresponding electron-dense deposits in the mesangium and/or the paramesangium on electron mi-

Manuscript accepted for publication February 20, 2014

a Department of Pathology, College of Medicine, King Saud University, Riyadh 11461, Saudi Arabia

${ }^{\mathrm{b}}$ Corresponding author: Sufia Husain, Department of Pathology and Laboratory Medicine, King Khalid University Hospital, King Saud University, PO Box 2925-11461, Riyadh, Saudi Arabia.

Email: suhusain@ksu.edu.sa

doi: http://dx.doi.org/10.14740/wjnu148w croscopy (EM) and 3) absence of any clinical or serological evidence of systemic lupus erythematosus (SLE). Since type I membranoproliferative glomerulonephritis can also exhibit strong C1q staining, it has been added as an exclusion criterion.

C1qN commonly presents as steroid-resistant nephrotic syndrome (SRNS) in children and young adults. The histological picture is variable and ranges from glomeruli with normal appearance to mesangial proliferation to segmental glomerular sclerosis. $\mathrm{C} 1 \mathrm{qN}$ lies in the spectrum between minimal change disease (MCD) and focal segmental glomerular sclerosis (FSGS). We present two cases of C1qN identified in Saudi Arabia, highlight the heterogeneity of this disease and review the literature.

\section{Case Report}

\section{Case 1}

A 39-year-old non-diabetic, normotensive man presented with mild generalized swelling without history of recent or past infection. Laboratory tests revealed sub-nephrotic range proteinuria $(0.36 \mathrm{~g} /$ day $)$ and microscopic hematuria. Serum values of albumin $(37.0 \mathrm{~g} / \mathrm{L})$, creatinine $(67 \mu \mathrm{mol} / \mathrm{L})$, complements $(\mathrm{C} 3: 1.21 \mathrm{~g} / \mathrm{L}$ and $\mathrm{C} 4: 0.203 \mathrm{~g} / \mathrm{L})$ and urea $(3.0$ $\mathrm{mmol} / \mathrm{L}$ ) were within normal limits.

\section{Case 2}

An 8-year-old boy with history of nephrotic syndrome since 2 years of age presented with resistance to treatment. Laboratory tests indicated presence of nephrotic range proteinuria $(25.98 \mathrm{~g}$ /day). Serum albumin was low $(20.0 \mathrm{~g} / \mathrm{L})$. Serum creatinine $(32 \mu \mathrm{mol} / \mathrm{L})$ and serum urea $(2.0 \mathrm{mmol} / \mathrm{L})$ were within normal limits. There was no hematuria.

Anti-streptolysin $\mathrm{O}$ titer, anti-nuclear antibody, doublestranded DNA, hepatitis B surface antigen, HCV antibody and anti-neutrophilic cytoplasmic antibodies were negative in both patients. A renal biopsy was performed in both patients.

The tissue samples obtained were processed for light 

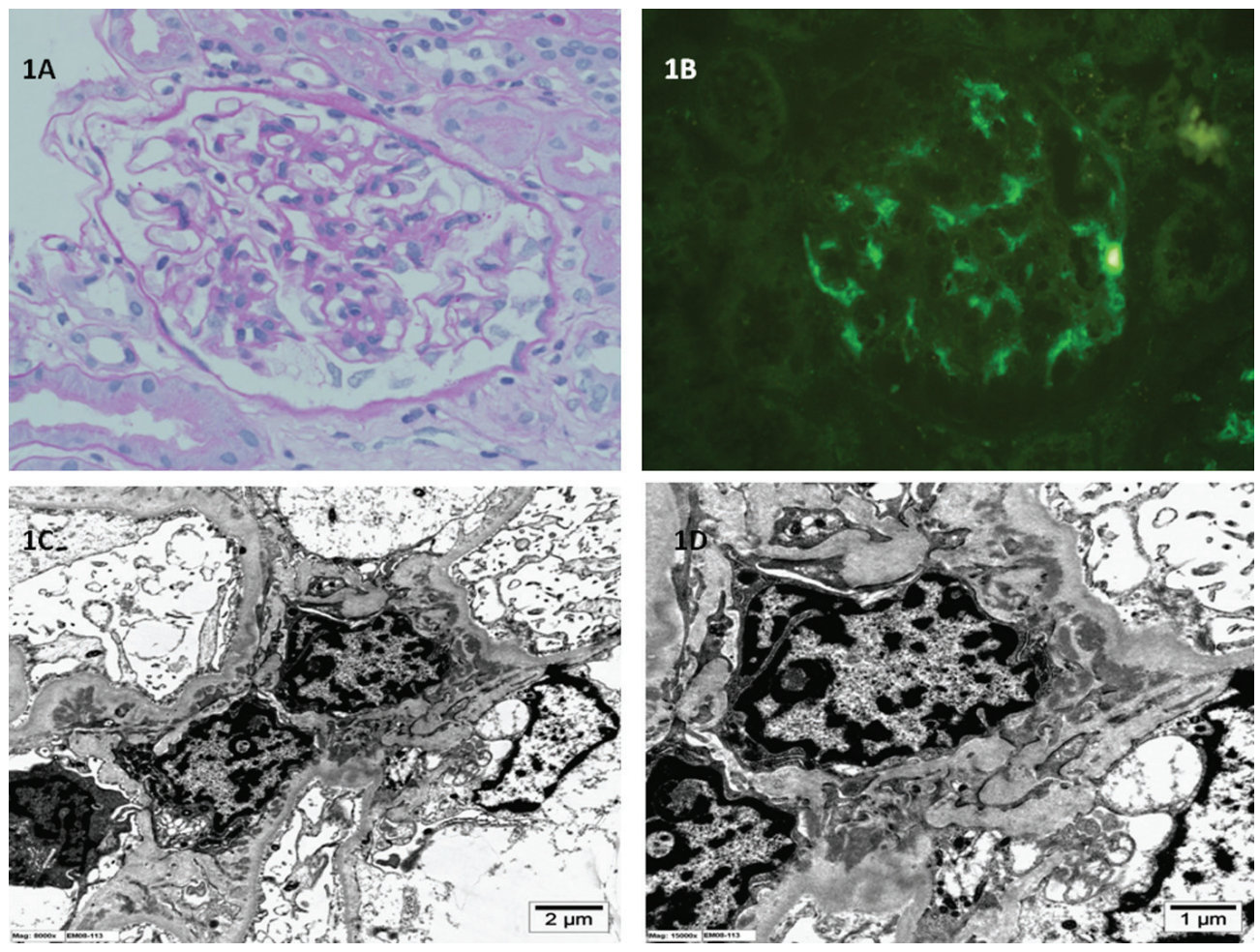

Figure 1. (A) Light microscopy of kidney biopsy specimen shows mild mesangial proliferation and mesangial matrix expansion (periodic acid-Schiff stain; original magnification $\times 400$ ). (B) Immunofluorescence microscopy of kidney biopsy specimen shows global mesangial staining with complement $\mathrm{C} 1 \mathrm{q}$ (anti-C1q antibody immunofluorescence; original magnification $\times 400)$. (C, D) Electron microscopy of kidney biopsy specimen shows electron dense immune deposits in the glomerular mesangium with extension into the paramesangium (uranyl acetate, lead citrate stain; original magnification $\times 8,000$ and $\times 15,000$ respectively).

microscopy, IF (IgA, IgG, IgM, C3, C1q, fibrinogen and albumin) and EM. Case 1 biopsy showed diffuse mesangial proliferation and matrix expansion with no sclerosis (Fig. 1). Case 2 biopsy showed segmental sclerosis in about $30 \%$ of the glomeruli examined and minimal mesangial proliferation (Fig. 2). Neither showed any extracapillary or endocapillary proliferation. IF showed dominant diffuse granular mesangial staining with $\mathrm{C} 1 \mathrm{q}$ in biopsy samples from both patients. In case $1, \operatorname{IgG}, \operatorname{IgM}$ and $\mathrm{C} 3$ mesangial staining were less intense, whereas IgA was negative. In case $2, \operatorname{IgM}$ and $\operatorname{IgG}$ were weakly positive and the remaining reactants were negative. EM demonstrated few electron-dense deposits in the mesangium with patchy effacement of the podocytes in both cases; however, the effacement was more widespread in case 2 . The glomerular basement membrane was of normal thickness. No tubule-reticular inclusions were identified in either case. $\mathrm{C} 1 \mathrm{qN}$ was diagnosed after examination of biopsy specimens from both patients.

\section{Discussion}

$\mathrm{C} 1 \mathrm{qN}$ is characterized by the presence of a dominant or co- dominant deposition of $\mathrm{C} 1 \mathrm{q}$ in the mesangium as evidenced on IF and EM, in the absence of any clinical or serological evidence of SLE. Furthermore, absence of a membranoproliferative pattern and hypocomplementemia has been added to the diagnostic criteria [2-4]. The extent of effacement of the podocytes correlates with the degree of proteinuria. Tubuloreticular inclusion bodies are typically absent. The diagnosis of $\mathrm{ClqN}$, similar to IgA nephropathy, is primarily based on the presence of a dominant/co-dominant reactant on IF with corresponding deposits on EM. It is an underreported diagnosis since many institutes do not routinely perform C1q staining for IF examination of kidney biopsy specimens.

The global incidence of $\mathrm{ClqN}$ in the biopsied pediatric population ranges from $1.9 \%$ to $6.6 \%$ [5]. The incidence in children biopsied for SRNS is 16\% [6]. The global prevalence of $\mathrm{C} 1 \mathrm{qN}$ ranges from $0.21 \%$ to $4 \%[2,3,7,8]$. The prevalence in our hospital has been $0.40 \%$ from 2009 to 2013.

Clinically, C1qN tends to occur in children; however, the age range can vary [7]. In the cases reported herein, one patient was an 8-year-old boy and the other was a 39-yearold man. C1qN commonly presents as relapsing or SRNS. It 

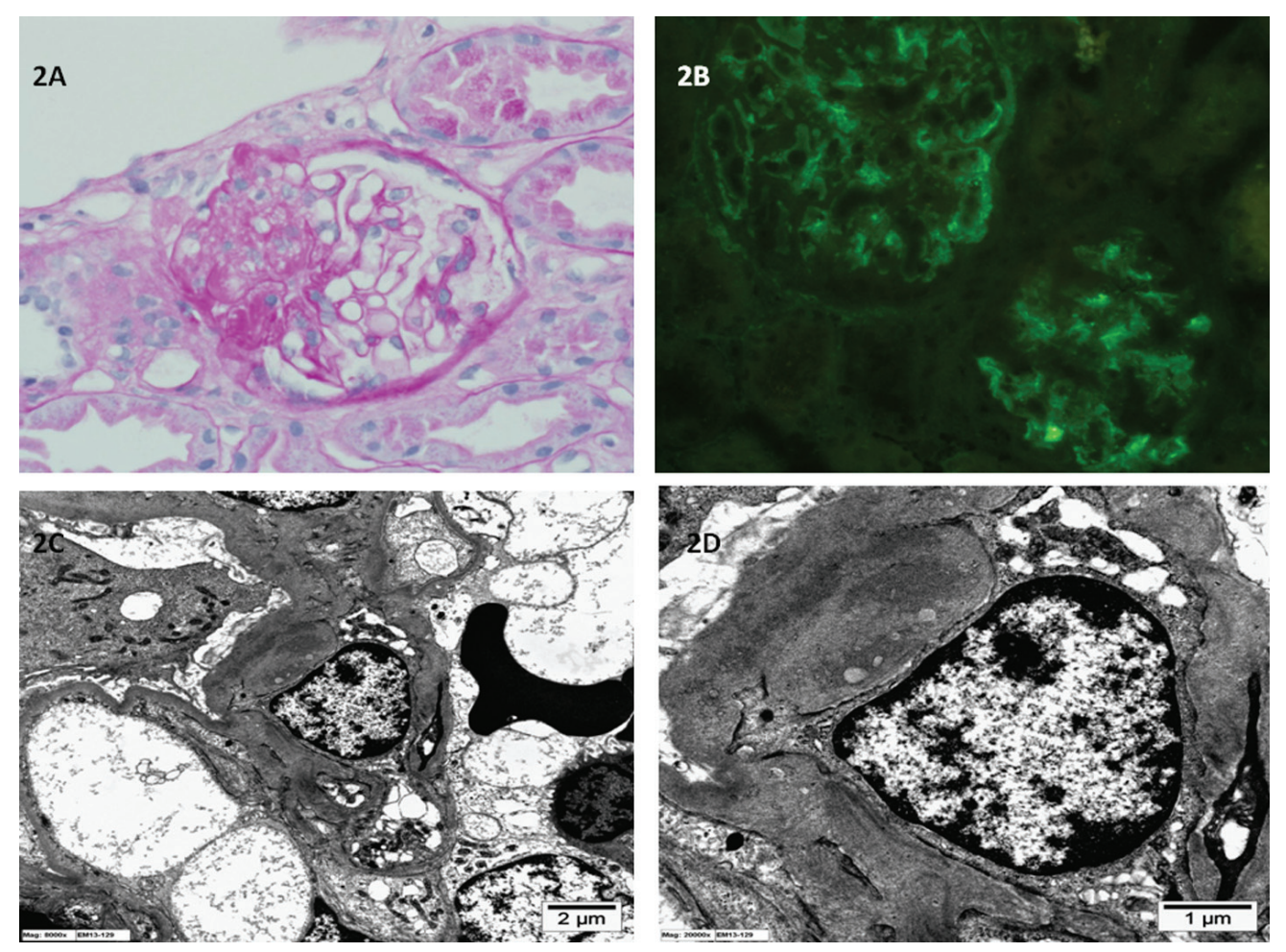

Figure 2. (A) Light microscopy of kidney biopsy specimen shows segmental sclerosis and the glomerular, basement membrane is of normal thickness (periodic acid-Schiff stain; original magnification $\times 400$ ). (B) Immunofluorescence microscopy of kidney biopsy specimen shows global mesangial staining with complement $\mathrm{C} 1 \mathrm{q}$ (anti-C1q antibody immunofluorescence; original magnification $\times 400)$. (C, D) Electron microscopy of kidney biopsy specimen shows electron dense immune deposits in the glomerular mesangium (uranyl acetate, lead citrate stain; original magnification $\times 8,000$ and $\times 20,000$ respectively).

can also present as sub-nephrotic proteinuria, microhematuria or chronic renal disease $[9,10]$.

There is significant heterogeneity in the findings of light microscopy with a wide spectrum of histological patterns, ranging from no glomerular alterations to focal or diffuse mesangial proliferation to focal segmental sclerosis [8]. Additionally, proliferative glomerulonephritis can occur rarely [8].

C1qN has been divided into two subsets: 1) podocytopathic type with podocyte effacement, proteinuria and an MCD to FSGS histology; and 2) immune complex-mediated type with hematuria or chronic kidney disease and focal to diffuse proliferative disease on histology [8]. Both of our cases were classified as podocytopathic type.

The etiopathogenesis of $\mathrm{ClqN}$ is not clear. $\mathrm{Clq}$ is produced mainly by antigen-presenting cells such as monocytes and macrophages, and its production is regulated by immune complexes, interferon gamma, lipopolysaccharides and corticosteroids $[11,12]$. C1q is the first complement of the classical pathway. The complement cascade is activated by the binding of $\mathrm{Clq}$ to the $\mathrm{Fc}$ receptors on IgG. Once $\mathrm{C} 1 \mathrm{q}$ is activated, the complement pathway is triggered, resulting in the formation of membrane attack complex.
$\mathrm{ClqN}$ is an idiopathic disease. Multiple mechanisms have been suggested for $\mathrm{C} 1 \mathrm{q}$ deposition in mesangial cells: 1) the passage of plasma proteins in the glomerulus leads to non-specific entrapment of these immunoglobulins in the mesangium and the $\mathrm{Clq}$ then binds to $\mathrm{Fc}$ receptors of these trapped immunoglobulins; 2) immune complex formation with $\mathrm{C} 1 \mathrm{q}$; 3) $\mathrm{C} 1 \mathrm{q}$ directly binds to receptors on the mesangial cells; and 4) increased synthesis of C1q by the macrophages triggered by inflammatory cytokines $[5,13]$.

$\mathrm{C} 1 \mathrm{qN}$ has been reported in association with Bartter syndrome [14], Gitelman syndrome [15] and in a case of chromosome 13 deletion with retinoblastoma [16]. C1qN development in early childhood was also reported in two siblings [17]. Collectively, these findings suggest the presence of genetic associations. However, no genetic testing was performed in our patients.

It may be argued that when other immunoglobulins are also positive on IF, the pathology actually involves seronegative lupus nephritis that ultimately becomes overt. Jones and Magil and Sharman et al reported such non-systemic mesangiopathic glomerulonephritis without progression to overt lupus nephritis $[1,18]$. Therefore, the term seronegative lupus nephritis is not useful. On the contrary, the term 
is confusing and can cause the patient considerable anxiety. In such cases, a diagnosis of $\mathrm{C} 1 \mathrm{qN}$ is more appropriate. Furthermore, circulating $\mathrm{C} 1 \mathrm{q}$ antibody, typically present in SLE, is absent in C1qN $[19,20]$. C1qN should also be distinguished from IgA nephropathy, in which IgA is the dominant stain instead of C1q. C1qN can also be confused with FSGS, but electron-dense immune deposits are very rare in a simple case of FSGS, vis-a-vis the characteristic deposits in the mesangium of a patient with $\mathrm{C} 1 \mathrm{qN}$.

The treatment of $\mathrm{ClqN}$ involves combinations of corticosteroids, calcineurin inhibitors and alkylating agents. Analysis of the published literature on $\mathrm{C} 1 \mathrm{qN}$ treatment in pediatric patients showed that $96 \%$ of patients were treated with corticosteroids, of which $66 \%$ had partial response, $30 \%$ were steroid-resistant and $14 \%$ progressed to endstage kidney disease (ESKD) [5]. Patients with nephrotic syndrome and MCD histology responded well to treatment and had good prognosis, while patients with FSGS morphology showed poor outcome, with almost 30\% progressing to ESKD. Kersnik et al and Vizjak et al reported similar findings $[8,9]$. Patients with nephrotic syndrome fared poorly compared to those without nephrotic syndrome [21]. Consistent with these findings, case 1 had only mild mesangial proliferation and responded well to corticosteroid treatment, currently being in complete remission. Case 2 had FSGS histology and showed poor response to cyclosporine combined with immunosuppressive therapy, currently being in partial remission. Therefore, the management and prognosis of $\mathrm{ClqN}$ is based not on the deposition of $\mathrm{Clq}$ but on the clinical picture, the biopsy findings on light microscopy, and the status of tubular atrophy and interstitial fibrosis. Perhaps this is why the status of $\mathrm{ClqN}$ as an established disease is controversial.

In summary, we report the cases of a child and an adult with $\mathrm{ClqN}$ with variable presentation, features and prognosis. We recommend that every relapsing or SRNS patient undergo kidney biopsy and that $\mathrm{C} 1 \mathrm{q}$ IF staining be routinely performed in examinations of all kidney biopsy specimens. Moreover, we also consider that $\mathrm{C} 1 \mathrm{qN}$ should be part of the differential diagnosis of proteinuria. Although $\mathrm{ClqN}$ is a controversial diagnosis and more studies are needed for this disease to become universally established and adopted, we suggest that $\mathrm{C} 1 \mathrm{qN}$ be classified as a separate clinicopathological entity, awaiting further study outcomes.

\section{Grant Support}

There is no support or funding for this manuscript.

\section{Conflicts of Interest}

There are no conflicts of interest with this manuscript.

\section{References}

1. Jones E, Magil A. Nonsystemic mesangiopathic glomerulonephritis with "full house" immunofluorescence. Pathological and clinical observation in five patients. Am J Clin Pathol. 1982;78(1):29-34.

2. Jennette JC, Hipp CG. C1q nephropathy: a distinct pathologic entity usually causing nephrotic syndrome. Am J Kidney Dis. 1985;6(2):103-110.

3. Jennette JC, Hipp CG. Immunohistopathologic evaluation of $\mathrm{Clq}$ in 800 renal biopsy specimens. Am J Clin Pathol. 1985;83(4):415-420.

4. Markowitz GS, Schwimmer JA, Stokes MB, Nasr S, Seigle RL, Valeri AM, D’Agati VD. C1q nephropathy: a variant of focal segmental glomerulosclerosis. Kidney Int. 2003;64(4):1232-1240.

5. Wenderfer SE, Swinford RD, Braun MC. C1q nephropathy in the pediatric population: pathology and pathogenesis. Pediatr Nephrol. 2010;25(8):1385-1396.

6. Wong CS, Fink CA, Baechle J, Harris AA, Staples AO, Brandt JR. C1q nephropathy and minimal change nephrotic syndrome. Pediatr Nephrol. 2009;24(4):761767.

7. Hisano S, Fukuma Y, Segawa Y, Niimi K, Kaku Y, Hatae K, Saitoh T, et al. Clinicopathologic correlation and outcome of C1q nephropathy. Clin J Am Soc Nephrol. 2008;3(6):1637-1643.

8. Vizjak A, Ferluga D, Rozic M, Hvala A, Lindic J, Levart TK, Jurcic V, et al. Pathology, clinical presentations, and outcomes of C1q nephropathy. J Am Soc Nephrol. 2008;19(11):2237-2244.

9. Kersnik Levart T, Kenda RB, Avgustin Cavic M, Ferluga D, Hvala A, Vizjak A. C1Q nephropathy in children. Pediatr Nephrol. 2005;20(12):1756-1761.

10. Nishida M, Kawakatsu H, Okumura Y, Hamaoka K. C1q nephropathy with asymptomatic urine abnormalities. Pediatr Nephrol. 2005;20(11):1669-1670.

11. Muller W, Hanauske-Abel H, Loos M. Biosynthesis of the first component of complement by human and guinea pig peritoneal macrophages: evidence for an independent production of the $\mathrm{C} 1$ subunits. J Immunol. 1978;121(4):1578-1584.

12. Lu JH, Teh BK, Wang L, Wang YN, Tan YS, Lai MC, Reid KB. The classical and regulatory functions of $\mathrm{C} 1 \mathrm{q}$ in immunity and autoimmunity. Cell Mol Immunol. 2008;5(1):9-21.

13. Colvin et al. Glomerular disease. In: Diagnostic pathology kidney diseases. 1st ed. Manitoba, Canada: Amirsys Publishing Inc. 2011;84-85.

14. Sardani Y, Qin K, Haas M, Aronson AJ, Rosenfield RL. Bartter syndrome complicated by immune complex nephropathy. Case report and literature review. Pediatr Nephrol. 2003;18(9):913-918.

15. Hanevold C, Mian A, Dalton R. C1q nephropathy in as- 
sociation with Gitelman syndrome: a case report. Pediatr Nephrol. 2006;21(12):1904-1908.

16. Roberti I, Sachdev S, Aronsky A, Kim DU. C1q nephropathy in a child with a chromosome 13 deletion. Pediatr Nephrol. 2006;21(5):737-739.

17. Kari JA, Jalalah SM. C1q nephropathy in two young sisters. Pediatr Nephrol. 2008;23(3):487-490.

18. Sharman A, Furness P, Feehally J. Distinguishing C1q nephropathy from lupus nephritis. Nephrol Dial Transplant. 2004;19(6):1420-1426.

19. Sinico RA, Radice A, Ikehata M, Giammarresi G, Cora- ce C, Arrigo G, Bollini B, et al. Anti-C1q autoantibodies in lupus nephritis: prevalence and clinical significance. Ann N Y Acad Sci. 2005;1050:193-200.

20. Trendelenburg M, Lopez-Trascasa M, Potlukova E, Moll S, Regenass S, Fremeaux-Bacchi V, Martinez-Ara J, et al. High prevalence of anti-C1q antibodies in biopsyproven active lupus nephritis. Nephrol Dial Transplant. 2006;21(11):3115-3121.

21. Lau KK, Gaber LW, Delos Santos NM, Wyatt RJ. C1q nephropathy: features at presentation and outcome. Pediatr Nephrol. 2005;20(6):744-749. 